\title{
Synthesis, crystal structure determination of two-dimensional supramolecular co-ordination polymer of silver(I) with 1,2-Bis(phenylthio)ethane and its Hirshfeld surface analysis
}

\author{
RAHUL K MUDSAINIYAN ${ }^{\mathrm{a}}$, AMANPREET K JASSAL ${ }^{\mathrm{a}}$, MEENU ARORA ${ }^{\mathrm{b}, *}$ and \\ SUKHVINDER K CHAWLA ${ }^{\text {a,* }}$ \\ ${ }^{a}$ Department of Chemistry, Guru Nanak Dev University, Amritsar 143 005, India \\ ${ }^{b}$ Department of Chemistry, Multani Mal Modi College, Patiala, 147001 India \\ e-mail: mudsainiyanrk@gmail.com; sukhvinder.k.chawla@gmail.com
}

MS received 28 July 2014; revised 19 December 2014; accepted 20 December 2014

\begin{abstract}
The 2-D polymeric complex (I) has the formula $\left[\mathbf{A g}(\mathbf{p h S E})\left(\mathbf{N O}_{\mathbf{3}}\right)\right]_{\mathbf{n}}$, which has been crystallized from methanol-acetonitrile mixture and characterized by elemental analysis and single-crystal X-ray diffraction analysis. In this polymer, each $\mathrm{Ag}(\mathrm{I})$ ion occupies distorted trigonal pyramidal geometry coordinating with two sulphur atoms from two different ligands and two oxygen atoms from two $\mathrm{NO}_{3}$ groups. Each $\mathrm{NO}_{3}$ acts as a bridging ligand coordinating through its two oxygen atoms to different $\mathrm{Ag}(\mathrm{I})$ ions. The $\mathrm{Ag}(\mathrm{I})$ ion and $\mathrm{NO}_{3}$ group are in plane with torsion angle $176.43^{\circ}$. All the ligands adopt anti-conformation but the relative orientation of two -S-C-C-S units is perpendicular to one another such that two phenyl rings attached to the two sulphur atoms coordinating to a particular $\mathrm{Ag}$ ion lie on the same side. Each $\mathrm{NO}_{3}$ bridges two neighbouring $\mathrm{Ag}$ ions belonging to two different -S-Ag-S-C-C-S-Ag-S- tapes running along $a$-axis where two phenyl rings are not parallel to each other to reduce the steric hindrance and maximize packing. The adjacent chains are fused to form 2D sheet by bridging both through bidentate phSE ligand and $\mathrm{NO}_{3}$ anion stacking in $a b$ plane. The structure consists of 4-c uninodal net where Point symbol for $\mathrm{Ag}$ (I) ion and net is $\left(4^{4} \cdot 6^{2}\right)$ with sql type topology. X-ray diffraction analysis and Hirshfeld surface analysis give rise to comparable results but in Hirshfeld surface analysis, twothird times more close contacts are obtained. The fingerprint plots demonstrate that these weak non-bonding interactions are important for stabilizing the crystal packing.
\end{abstract}

Keywords. Distorted trigonal pyramidal geometry; anti-conformation; steric hindrance; sql type topology; fingerprint plots

\section{Introduction}

$\mathrm{Ag}(\mathrm{I})$ being soft acid is often used for coordination to soft bases such as ligands containing sulphur and nitrogen donor atoms. ${ }^{1-6}$ Flexible ligands derived by the introduction of $\mathrm{R}$ into pyridyl rings of 4, 4-bpy and certain thioethers have been employed for the construction of polymers with $\operatorname{Ag}(\mathrm{I})$ salts. A series of complexes ranging from $1 \mathrm{D}$ to $3 \mathrm{D}$ architectures viz., $\left\{\left[\mathrm{Ag}(\mathrm{bpp})\left(\mathrm{CF}_{3} \mathrm{SO}_{3}\right)\right] \cdot \mathrm{EtOH}\right\}_{\mathrm{n}},\left[\mathrm{Ag}(\mathrm{bpp})\left(\mathrm{CF}_{3} \mathrm{SO}_{3}\right)\right]_{\mathrm{n}},\left[\mathrm{Ag}_{2}\right.$ (bpp $\left.)_{4}\left(\mathrm{CF}_{3} \mathrm{SO}_{3}\right)_{2} \cdot \mathrm{bpp}\right]_{\mathrm{n}},\left[\mathrm{Ag}(\mathrm{bpp})\left(\mathrm{ClO}_{4}\right)\right]_{\mathrm{n}}$ and $[\mathrm{Ag}(\mathrm{bpp})$ $\left.\left(\mathrm{PF}_{6}\right)\right]_{\mathrm{n}}\left(\mathrm{bpp}=2,2^{\prime}\right.$-bipyridine $)$ exhibiting different conformations of bpp have been synthesized. All the three triflate polymers have been obtained from same reaction mixture where bpp exhibits different conformations (TT, GG and TG respectively) in these networks. ${ }^{7}$ However, no polymer with GG conformation has so far been prepared. $\left[\mathrm{Ag}(\mathrm{bpp})\left(\mathrm{ClO}_{4}\right)\right]_{\mathrm{n}}$

*For correspondence can be transformed into $\left[\mathrm{Ag}(\mathrm{bpp})\left(\mathrm{NO}_{3}\right)\right]_{\mathrm{n}}$ via anion exchange. ${ }^{8}$ Similarly, complexes containing thioether ligands $\mathrm{C}_{6} \mathrm{H}_{5}-\mathrm{S}-\mathrm{R}-\mathrm{S}-\mathrm{C}_{6} \mathrm{H}_{5}$ are reported for $\mathrm{R}=$ methyl and butyl with $\mathrm{AgNO}_{3}$ and $\mathrm{AgClO}_{4}$. A chiral non-interpenetrated $3 \mathrm{D}$ helical cyclic network $\left[\mathrm{Ag}_{2}(\mathrm{phSM})_{3}\left(\mathrm{ClO}_{4}\right)\right]_{\mathrm{n}}$ is prepared by reacting $\mathrm{AgClO}_{4}$ with phSM [Bis(phenylthio)methane]. ${ }^{9}$ The analogous reaction of $\mathrm{AgNO}_{3}$ with phSM resulted in 1D pseudo helical architecture because of coordination of $\mathrm{NO}_{3}$ to $\mathrm{Ag}(\mathrm{I})$ ion. ${ }^{10}$ However, $\left[\mathrm{Ag}_{2}(\mathrm{phSB})_{3}\left(\mathrm{ClO}_{4}\right)_{2}\right]_{\mathrm{n}}$, $\left[\mathrm{Ag}(\mathrm{phSB})_{2}\left(\mathrm{ClO}_{4}\right)\right]_{\mathrm{n}}$ and $\left[\mathrm{Ag}(\mathrm{phSB})\left(\mathrm{NO}_{3}\right)\right]_{\mathrm{n}}[\mathrm{phSB}=$ Bis(phenylthio)butane] are non-interpenetrated 2D networks. Out of the several probable conformations of butyl ligand only TTT and GTG conformations are observed in these complexes. Ag complexes with ethyl analogues of these ligands have been reported in literature. ${ }^{9,11}$ In order to investigate the influence of the length of spacer and increasing flexibility of ligand on the final architecture of the polymer, their ethyl analogues were prepared and compared with 
literature. In the study of coordination networks based on phSM, 1D-coordination polymers were obtained because the spacer length is too short and a central aliphatic segment containing odd number of methylene groups. It has been noted that chemically symmetrical molecules containing a central aliphatic segment with an even number of methylene groups often have a crystallographic centre of symmetry in the middle of the central $\mathrm{CH}_{2}-\mathrm{CH}_{2}$ bond. The free ligands bis(phenylthio) $\mathrm{X}$ (where $\mathrm{X}=$ butane, hexane, octane, etc.), which all contain an aliphatic sequence with an even number of $\mathrm{CH}_{2}$ groups, are in the fully extended conformation. So we can say that by increasing the length of spacer, extended form of conformations are obtained because of the flexibility in the aliphatic segment and several torsion angles. ${ }^{1 \mathrm{c}}$ To synthesize the complex (I), $\mathrm{AgNO}_{3}$ was reacted with phSE [Bis(phenylthio)ethane] in $\mathrm{CH}_{3} \mathrm{OH}-\mathrm{CH}_{3} \mathrm{CN}$ mixture. The elemental analysis for the complex (I) corresponds to formula $\left[\mathrm{Ag}(\mathrm{L})\left(\mathrm{NO}_{3}\right)\right]_{\mathrm{n}}\left(\mathrm{L}=\right.$ phSE) in $\mathrm{CH}_{3} \mathrm{OH}-$ $\mathrm{H}_{2} \mathrm{O}$ solution. This complex is non-interpenetrated two-dimensional (2D) network in solid state with 1,2bis(phenylthio)ethane ( $\mathbf{L}$ ) ligand as a building block. Molecular Hirshfeld surfaces calculations of complex (I) were performed by using the Crystal Explorer 3.1 $1^{12}$ which give details on non-bonding or weak interactions as well as interactions around $\operatorname{Ag}(\mathrm{I})$ metal ion.

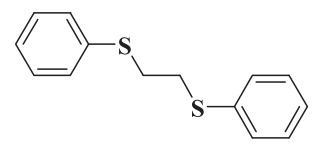

$\mathbf{L}$

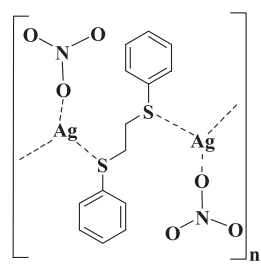

Complex (I)

\section{Experimental}

\subsection{Synthesis of $\left[\mathrm{Ag}(\mathrm{phSE})\left(\mathrm{NO}_{3}\right)\right]_{n}$}

To an aqueous solution of $\mathrm{AgNO}_{3}(0.17 \mathrm{~g}, 1.0 \mathrm{mmol}$ in $10 \mathrm{~mL})$ was added methanol solution of phSE $(0.46 \mathrm{~g}$, $2.0 \mathrm{mmol}$ in 15). The reaction mixture was refluxed for one hour. White precipitate of complex separated out upon cooling, which was filtered, dissolved in $\mathrm{CH}_{3} \mathrm{OH}-\mathrm{CH}_{3} \mathrm{CN}$ mixture and left undisturbed for a period of one week to get crystals suitable for X-ray studies. Yield $70 \%$, found (\%) for $\mathbf{C}_{\mathbf{1 4}} \mathbf{H}_{\mathbf{1 4}} \mathbf{A g N O} \mathbf{O}_{\mathbf{3}} \mathbf{S}_{\mathbf{2}}$; $\mathrm{C}, 39.2 ; \mathrm{H}, 3.6 ; \mathrm{N}, 3.7$; calcd. $\mathrm{C}, 40.3 ; \mathrm{H}, 3.3$; $\mathrm{N}, 3.3$.

\subsection{Physical measurements}

All the starting reagents of analytical grade were used without further purification. $\mathrm{C}, \mathrm{H}, \mathrm{N}$ elemental analyses were obtained with a CHNS-O analyzer flesh-EA-1112 series. Single crystal structural X-ray diffraction was carried out on a Bruker's Apex-II CCD Diffractometer using $\mathrm{Mo} \mathrm{K} \alpha(\lambda=0.71069)$ at temperature of $-100 \mathrm{~K}$. Molecular Hirshfeld surface calculations of complex (I) were performed by using the Crystal Explorer 3.1. The $3 \mathrm{D} d_{\text {norm }}$ surfaces are mapped over a fixed colour scale of -1.25 (red) to $1.52 \AA$ (blue), Shape index mapped in the colour range of -1.0 to $1.0 \AA$ and Curvedness in the range of -4.0 to $0.4 \AA$. The $2 \mathrm{D}$ fingerprint plots are displayed by using the standard $0.58-2.7 \AA$ view, with the $\mathrm{d}_{\mathrm{e}}$ and $\mathrm{d}_{\mathrm{i}}$ distance scales as displayed on the graph axes.

\section{$2.3 X$-ray diffraction}

The crystals were grown by slow evaporation at room temperature and X-ray data of this complex was collected on a Bruker's Apex-II CCD diffractometer using Mo $\mathrm{K} \alpha(\lambda=0.71069)$ at temperature of $-100 \mathrm{~K}$. The data collected by CCD diffractometer were processed by SAINT. ${ }^{13}$ Lorentz and polarization effects and empirical absorption corrections were applied using SADABS ${ }^{14}$ from Bruker. The structure was solved by direct methods, using SIR- $92^{15}$ and refined by fullmatrix least squares refinement methods ${ }^{16}$ based on $\mathrm{F}^{2}$, using SHELX-97. ${ }^{17}$ All non-hydrogen atoms were refined anisotropically. All hydrogen atoms of bipyridyl ring were fixed geometrically with their $U_{\text {iso }}$ values 1.2 times of their carrier carbons. Geometry of this complex and hydrogen bonding interactions were calculated using PARST programme. ${ }^{18}$ All the drawings of complexes were made using ORTEP $^{19}$ and MERCURY ${ }^{20}$ programs. All calculations were performed using Wingx package. ${ }^{21}$

\subsection{Hirshfeld surface calculations}

A Hirshfeld surface analysis ${ }^{22}$ is a technique used to visualize the different intermolecular interactions within molecule employing to find out the 3D molecular surface contours. The Hirshfeld surfaces in the crystal structure of particular complex are constructed on the basis of calculated electron distribution calculated as the sum of spherical atom electron densities. Inside the Hirshfeld surface, the electron distribution due to a sum of spherical atoms for the molecule (the promolecule) dominates the corresponding sum over the crystal (the pro-crystal). The 2D fingerprint plots have 
also been used to examine molecular shapes and give the exact percentage of all important intermolecular contacts. Many applications in the recent past demonstrated that this analysis can be very valuable in the exploration of the packing modes and intermolecular contacts. ${ }^{23}$ Distances from points on the surface to a nucleus (atom) inside $\left(\mathrm{d}_{\mathrm{i}}\right)$ and outside $\left(\mathrm{d}_{\mathrm{e}}\right)$ the mean surface are determined by the differing vdW radii of atoms, whereby the contact distances $d_{i}$ and $d_{e}$ can be normalized $\left(d_{\text {norm }}\right)$. Therefore, intermolecular interactions (short, moderate, long) in a crystal structure resulting from hydrogen bond donors/acceptors can be visually represented by Hirshfeld surfaces. The value of $d_{\text {norm }}$ is - ve or +ve when intermolecular contacts are shorter or longer than van der Waals radii, respectively. The 2D fingerprint plots summarize the nature and type of intermolecular contacts experienced by the molecules in the crystal. For each crystal structure, the Hirshfeld surfaces as well as fingerprint plots are unique, and the number of unique Hirshfeld surfaces depends on the number of crystallographically independent molecules in the corresponding asymmetric unit.

\section{Results and Discussion}

\subsection{Crystal structure of $\left[\mathrm{Ag}(\mathrm{phSE})\left(\mathrm{NO}_{3}\right)\right]_{n}$}

Single crystal X-ray diffraction studies reveal that $\left[\mathrm{Ag}(\mathrm{phSE})\left(\mathrm{NO}_{3}\right)\right]_{\mathrm{n}}$ crystallizes in Monoclinic centrosymmetric space group $\mathrm{P} 2{ }_{1} / \mathrm{c}$ (space group no. 14). Figure 1 depicts the asymmetric unit along with numbering scheme where each $\operatorname{Ag}(\mathrm{I})$ ion involves a

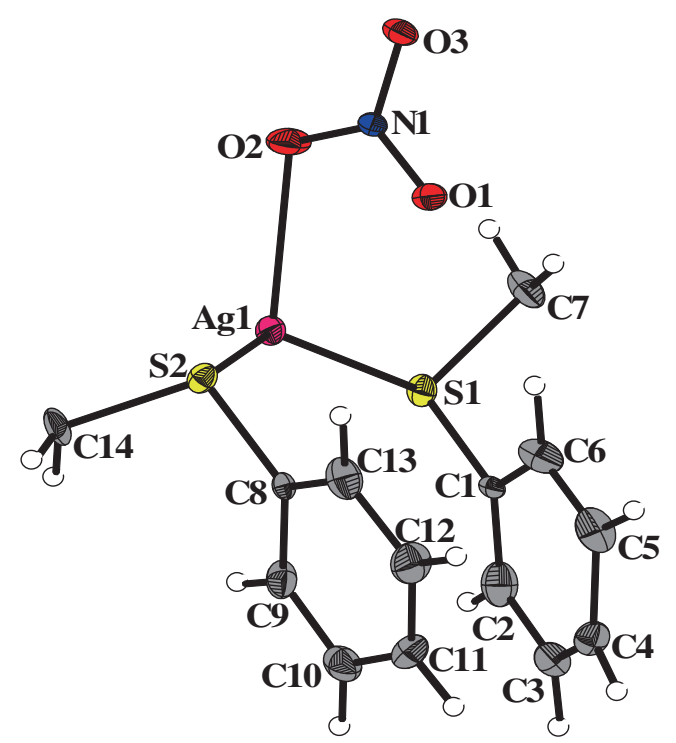

Figure 1. ORTEP showing asymmetric unit of complex (I) (with $20 \%$ probability). distorted trigonal pyramidal coordination geometry (figure 2a) comprising two sulphur atoms from two different ligands and two oxygen atoms from two $\mathrm{NO}_{3}$ groups. Each $\mathrm{NO}_{3}$ acts as a bridging ligand coordinating through its two oxygen atoms to different $\mathrm{Ag}(\mathrm{I})$ ions. The $\operatorname{Ag}(\mathrm{I})$ ion and $\mathrm{NO}_{3}$ group are in plane with torsion angle $176.43^{\circ}$ and distortion around $\mathrm{Ag}(\mathrm{I})$ ion can be understood from the base angles $\mathrm{S}(2)-\mathrm{Ag}(1)$ $\mathrm{S}(1)$ is $137.43^{\circ}, \mathrm{O}(2)-\mathrm{Ag}(1)-\mathrm{S}(1)$ is $104.71^{\circ}$ and $\mathrm{O}(2)-$ $\mathrm{Ag}(1)-\mathrm{S}(2)$ is $105.19^{\circ}$, sum of which is $347.33^{\circ}$. The apical site is occupied by oxygen atom from $\mathrm{NO}_{3}$ ion of another layer with bond angle of $\mathrm{O}(2)-\mathrm{Ag}(1)-\mathrm{O}(3)^{\# 1}$ is $90.60(4)^{\circ}, \mathrm{O}(3)^{\# 1}-\mathrm{Ag}(1)-\mathrm{S}(2)$ is $106.3(3)^{\circ}$ and $\mathrm{O}(3)^{\# 1}$ $\mathrm{Ag}(1)-\mathrm{S}(1)$ is $103.0(3)^{\circ}$ (\#1: $\left.\mathrm{x}-1, \mathrm{y}, \mathrm{z}\right)$. The Ag-S distance (2.51 $\AA$ average) and Ag-O distance (2.46 $\AA$ average) are in accordance with the earlier reported thioether and $\mathrm{NO}_{3}$-briged complexes. ${ }^{11}$ Each phSE ligand bridges two adjacent $\mathrm{Ag}$ ions to form a zigzag tape along $b$ axis with S. ...S separation is $4.676 \AA$ (figure $2 b$ ). All the ligands adopt anti-conformation but the relative orientation of two -S-C-C-S units is perpendicular to one another such that two phenyl rings attached to the two sulphur atoms coordinating to a particular $\mathrm{Ag}$ ion lie on the same side (figure $3 \mathrm{a}$ ). Each $\mathrm{NO}_{3}$ bridges two neighbouring $\mathrm{Ag}$ ions belonging to two different $-\mathrm{S}-\mathrm{Ag}-$ $\mathrm{S}-\mathrm{C}-\mathrm{C}-\mathrm{S}-\mathrm{Ag}-\mathrm{S}$ - tapes running along $a$-axis where two phenyl rings are not parallel to each other to reduce the steric hindrance and maximize packing are clearly shown (figure 3b). The adjacent chains are, therefore, fused to form 2D sheet by bridging both through bidentate phSE ligand and $\mathrm{NO}_{3}$ anion stacking in $a b$ plane (figure $4 \mathrm{a}-\mathrm{b})$. In the criss-cross chains formed by (-S$\mathrm{Ag}-\mathrm{S}-\mathrm{C}-\mathrm{C}-\mathrm{S}-\mathrm{Ag}-\mathrm{S}-$ ) and -O-Ag-O-N-O-Ag-, there is a long cavity along $b$-axis where phenyl rings are placed and are within $\pi-\pi$ interaction range i.e., $3.851 \AA$ (figure 5a). In another description of the crystal structure of complex, the $\operatorname{Ag}(\mathrm{I})$ ions and coordinated nitrate groups alternate in a linear arrangement and $\mathbf{L}$ crosslinks adjacent chains to form a 2D network. In the two types of repeating units, four $\mathrm{Ag}(\mathrm{I})$ atoms are nearly coplanar, and the dihedral angle between the mean planes of the two types of units is $152.69(6)^{\circ}$. The two phenyl rings at the ends of the ligands are parallel to each other and alternate 'above' and 'below' the repeating unit. Units $\mathbf{A}(\mathrm{L})$ and $\mathbf{B}\left(\mathrm{NO}_{3}\right.$ anion) stack alternately along the crystallographic $b$-axis, and each propagates along the $a$ - and $b$-axes to form an infinite $2 \mathrm{D}$ framework. The structure consists of 4-c uninodal net where Point symbol for Ag (I) ion and net is $\left(4^{4} .6^{2}\right)$ with sql type topology (figure 5 b). Crystal data and structure refinements for complex (I) are given in table 1, while weak $\mathrm{H}$-bonding interactions between $\mathrm{O}$ atoms of $\mathrm{NO}_{3}$ group and protons of the phenyl ring of 


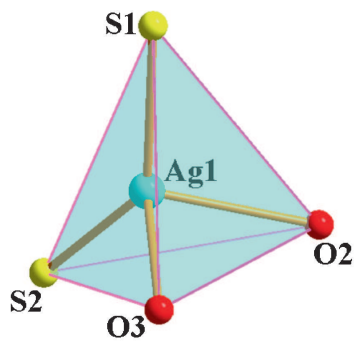

(a)

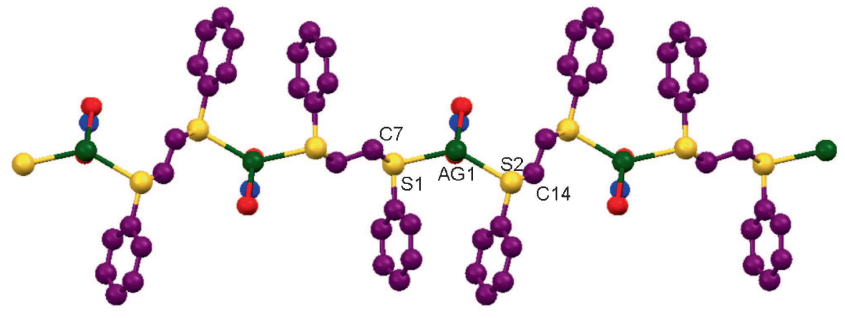

(b)

Figure 2. (a) Polyhedra around $\mathrm{Ag}(\mathrm{I})$ ion show distorted trigonal pyramidal geometry; (b) 1-D linear tape is formed along $b$ axis in complex (I).

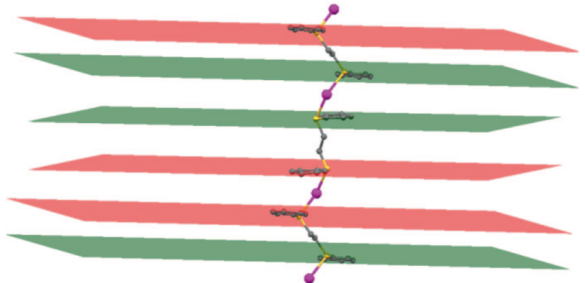

(a)

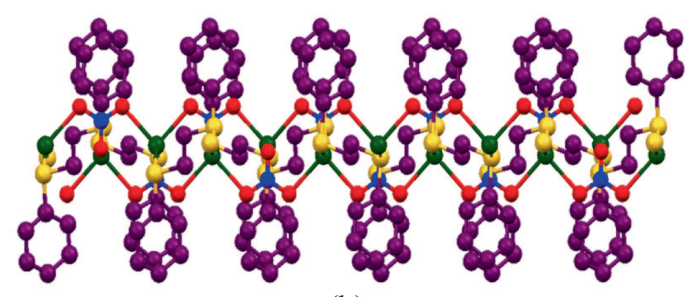

(b)

Figure 3. (a) Planes of different colour show anti-conformation of $\mathbf{L}$ in the complex due to flexibility and to reduce the stearic hindrance; (b) 1-D linear chain is formed along $a$ axis in complex (I).

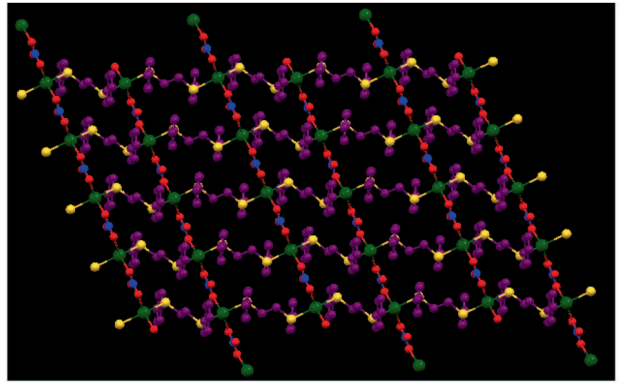

(a)

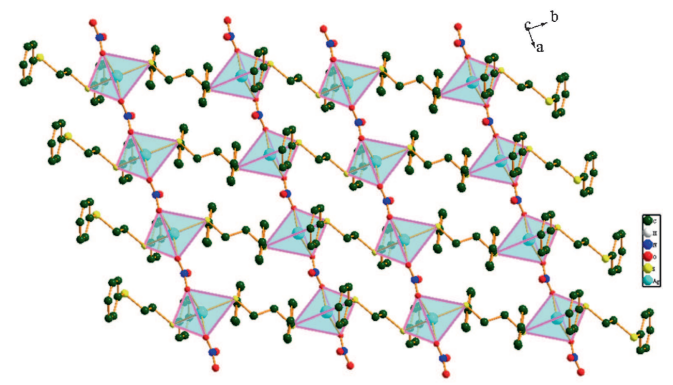

(b)

Figure 4. (a) Ball-n-stick model; (b) Polyhedral representation of 2-D sheet or network as shown in $a b$ plane of complex (I).

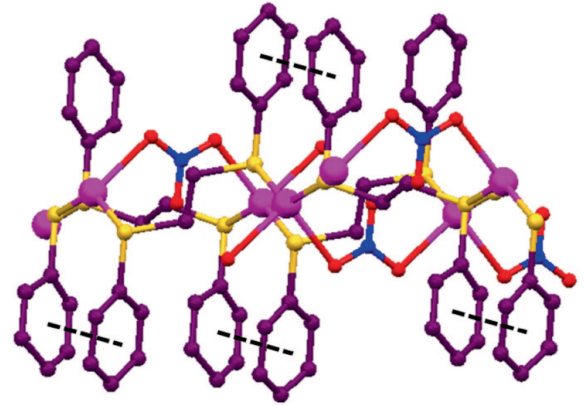

(a)

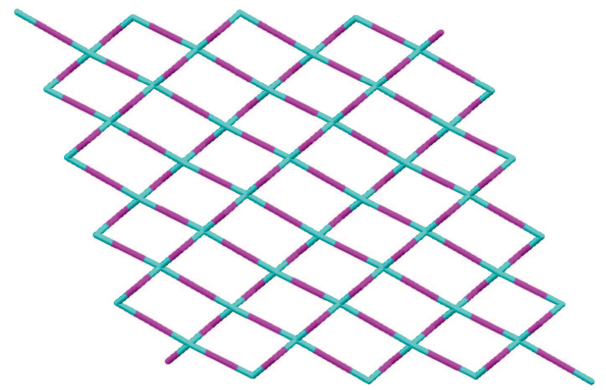

(b)

Figure 5. (a) $\pi-\pi$ interactions between two phenyl rings are shown in the range of $3.851 \AA$ A (b) 4-c uninodal net is shown; $\left(4^{4} .6^{2}\right)$ point symbol for net with sql type topology in complex (I). 
Table 1. Crystal data and structure refinement for complex (I).

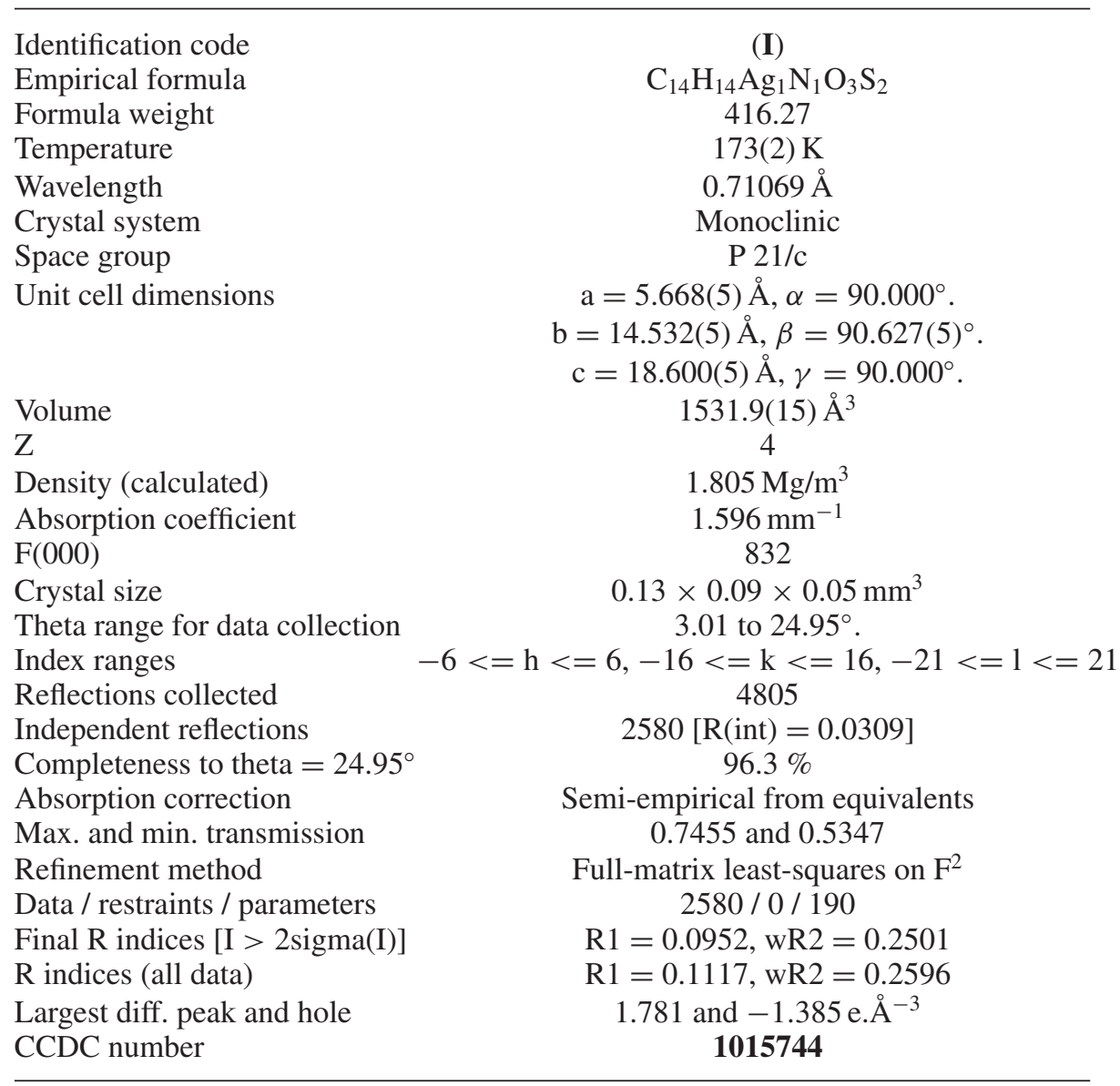

adjacent chain are shown in table 2. Complete listings of the bond distances, bond angles and torsion angles around Ag (I) ion are included in the supplemental material (table TS1).

$\mathrm{Bu}$ et al. have earlier reported $\left[\mathrm{Ag}(\mathrm{phSM})\left(\mathrm{NO}_{3}\right)\right]_{\mathrm{n}}$ and $\left[\mathrm{Ag}(\mathrm{phSB})\left(\mathrm{NO}_{3}\right)\right]_{\mathrm{n}}$ complexes which exhibits 1D pseudo helical and 2D frameworks respectively. ${ }^{9,11}$ The pseudo helical structure instead of 2D architecture in case of phSM can be attributed to smaller length of spacer. The $\mathrm{NO}_{3}$ bridging might have been avoided due to greater steric hindrance of the phenyl groups of ligand. However, in case of ethyl analogues of phSM, the length of ligand is sufficiently large to allow the $\mathrm{NO}_{3}$ ion to bridge two neighbouring chains without any crowding of the phenyl groups to generate noninterpenetrated 2D networks.

Table 2. Important H-bonding interactions of complex (I).

\begin{tabular}{|c|c|c|c|c|}
\hline X-H...Y & X...H & $\mathrm{X} \ldots \mathrm{Y}$ & H...Y & $\angle \mathrm{X}-\mathrm{H} \ldots \mathrm{Y}$ \\
\hline C6-H6...O1 & 0.95 & 3.66 & $2.78(10)$ & 155 \\
\hline C7-H7B...O1 & 0.99 & 3.54 & $2.82(11$ & 129 \\
\hline $\mathrm{C} 4-\mathrm{H} 4 \ldots \mathrm{O} 2^{1}$ & 0.95 & 3.31 & $2.62(12$ & 130 \\
\hline $\mathrm{C} 5-\mathrm{H} 5 \ldots \mathrm{O} 2^{1}$ & 0.95 & 3.46 & $2.94(12$ & 116 \\
\hline $\mathrm{C} 11-\mathrm{H} 11 \ldots \mathrm{O} 2^{1}$ & 0.95 & 3.44 & $2.91(13$ & 117 \\
\hline $\mathrm{C} 10-\mathrm{H} 10 \ldots 3^{2}$ & 0.95 & 3.29 & $2.74(11$ & 117 \\
\hline $\mathrm{C} 4-\mathrm{H} 4 \ldots \mathrm{O}^{2}$ & 0.95 & 3.32 & $2.60(11$ & 132 \\
\hline $\mathrm{C} 11-\mathrm{H} 11 \ldots 3^{2}$ & 0.95 & 3.28 & $2.67(12$ & 122 \\
\hline C14-H14A...O1 ${ }^{3}$ & 0.99 & 3.46 & $2.69(11$ & 135 \\
\hline C14-H14B...O3 ${ }^{4}$ & 0.99 & 3.51 & $2.62(12$ & 150 \\
\hline (1) $\mathrm{x},-\mathrm{y}+1 / 2,+\mathrm{z}-1 / 2$ & (2) $x-1$ & $1 / 2,+z-1 / 2$ & (3) $\mathrm{x}-1,+\mathrm{y},+\mathrm{z}$ & (4) $-x+2,-y,-z+$ \\
\hline
\end{tabular}




\subsection{Molecular Hirshfeld surfaces}

Hirshfeld surface is a useful tool for describing characteristic of the molecules. In this work we performed Hirshfeld surfaces to complex (I) and compared it with earlier reported complexes $\left[\mathrm{Ag}(\mathrm{phSD})\left(\mathrm{NO}_{3}\right)\right]_{\mathrm{n}}$ (II) and $\left[\mathrm{Ag}(\mathrm{phSE})\left(\mathrm{CF}_{3} \mathrm{SO}_{3}\right)\right]_{\mathrm{n}}(\mathrm{III})^{1 \mathrm{c}}$ with the purpose to investigate the influence of spacer length and nature of anion on the intermolecular interactions experienced in these three complexes. The 3D $d_{\text {norm }}$ surfaces are mapped over a fixed colour scale of -1.25 (red) to $1.52 \AA$ (blue), Shape index mapped in the colour range of -1.0 to $1.0 \AA$ and Curvedness in the range of -4.0 to $0.4 \AA$.

In these complexes, owing to the presence of $\mathrm{O}, \mathrm{N}$, $\mathrm{S}, \mathrm{F}$ (in the (III) complex), $\mathrm{C}, \mathrm{Ag}$ and $\mathrm{H}$ atoms, a large number of van der Waals interactions viz., H. .H, O...H, F..H, C..H, S..H, N...H, C...C, S..O, C...N, O..O, Ag...O and Ag...H are observed. Figure 6 depicts the molecular Hirshfeld surfaces $d_{\text {norm }}$, Shape indexes and Curvedness of the complexes. Relative contributions to the Hirshfeld surface area for the various intermolecular contacts in complexes are given in table 3 .
Table 3. Summary of various contact contributions to the complexes (I)-(III).

\begin{tabular}{lccc}
\hline (\% age) & (I) & (II) & (III) \\
\hline H...H & 40.2 & 61.7 & 10.7 \\
O...H & 23.7 & 17.8 & 19.4 \\
C...H & 17.1 & 10 & 11.1 \\
S...H & 8.5 & 4.7 & 1.3 \\
C... & 4.3 & 1.2 & 1.5 \\
S...O & 2 & 0 & 1.3 \\
N...H & 1.2 & 1.8 & 0 \\
O... & 1.1 & 0.1 & 3.2 \\
Ag... & 0.6 & 2.5 & 6.7 \\
Ag...H & 0.6 & 0.1 & 2.5 \\
H...F & 0.0 & 0.0 & 30.3 \\
\hline
\end{tabular}

The $d_{\text {norm }}$ surface is used for the identification of very close intermolecular interactions and their values are mapped onto the Hirshfeld surface by using a redblue-white colour scheme, where red concave regions correspond to dominant interactions with negative $d_{n o r m}$ value; the blue regions correspond to weaker contacts and positive $d_{\text {norm }}$ value; and the white

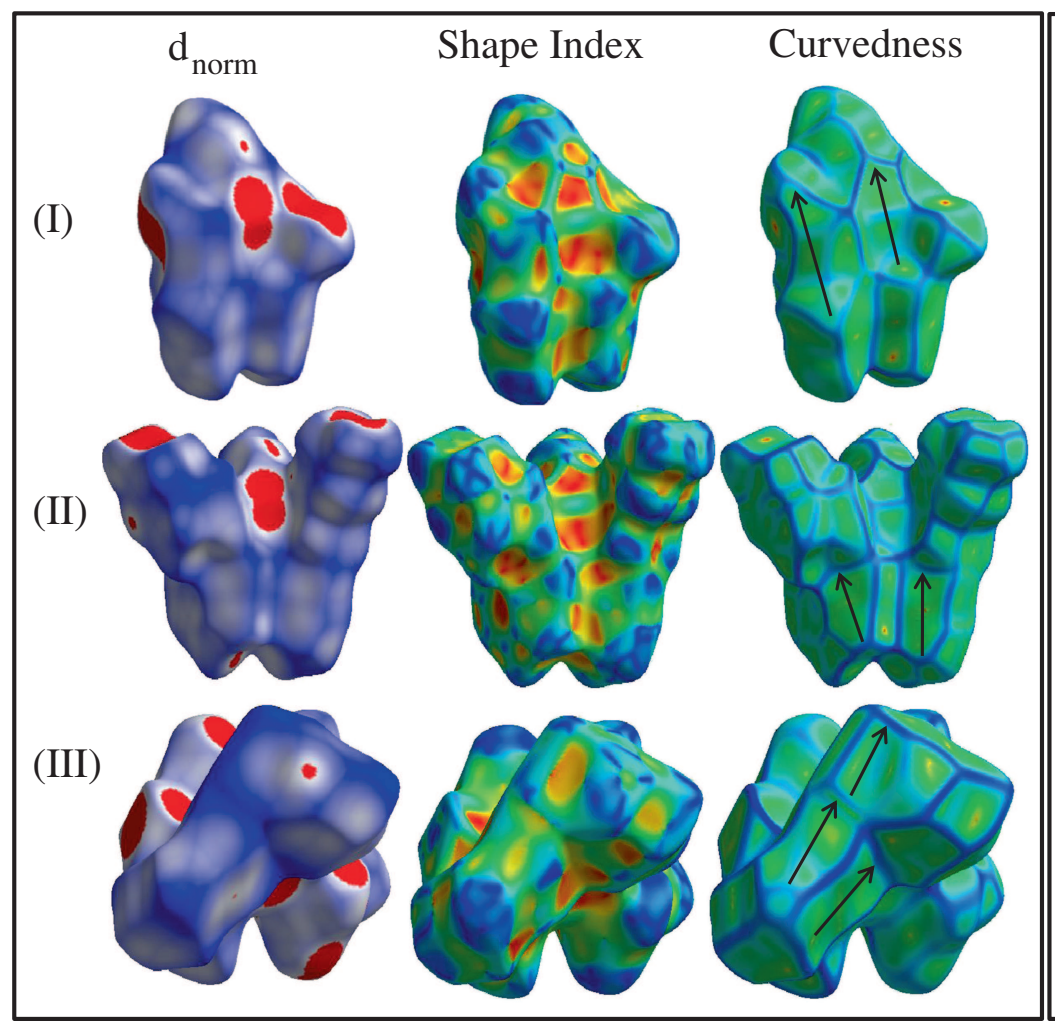

(a)

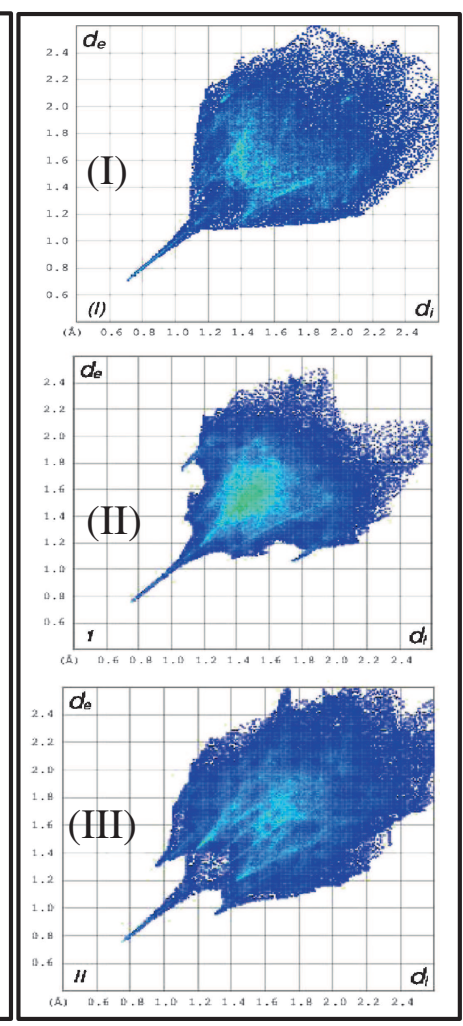

(b)

Figure 6. (a) Molecular Hirshfeld $d_{\text {norm }}$ surfaces, Shape index and Curvedness of complexes (I), $\left[\mathbf{A g}(\mathbf{p h S D})\left(\mathbf{N O}_{\mathbf{3}}\right)\right]_{\mathbf{n}}(\mathbf{I I})^{1 \mathrm{c}}$ and $\left[\mathbf{A g}(\mathbf{p h S E})\left(\mathbf{C F}_{\mathbf{3}} \mathbf{S O}_{\mathbf{3}}\right)\right]_{\mathbf{n}}(\mathbf{I I I})^{\mathrm{lc}}$, where $\mathrm{d}_{\mathrm{e}}$ surfaces have been mapped between $\mathrm{d}_{\mathrm{e}} 0.58$ and $2.7 \AA$; (b) 2D fingerprint plot of complexes (I)-(III) where areas of different intermolecular contacts are clearly shown. 
regions correspond to the contacts where the distance is exactly the van der Waal separation with zero $d_{\text {norm }}$ value. ${ }^{24-26}$

In our study, the concave red patches on the $d_{\text {norm }}$ surfaces (figure 6a) reveal strong interactions from O...H, N...H bonding in these complexes. However, the corresponding red area in complex (III) is significantly larger suggesting strong F...H bonding apart from O...H and N...H contacts. Actually hydrogen bonding interactions to electronegative atoms like O, N, F contribute $24.9,19.6$ and $49.7 \%$ to the Hirshfeld surfaces in complexes (I), (II) and (III) respectively.

The Shape index is most sensitive to very subtle changes in the shape of surface; several small scattered yellow-red concave patches on them reveal weak intermolecular interactions from phenyl, C, S, Ag and $\mathrm{H}$ atoms of the complexes. ${ }^{27}$ Curvedness conveys the similar information as Shape index, which is the measurement of 'how much shape.' The Curvedness surfaces of all the complexes exhibit several small flat segments delineated by blue outline which suggest the absence of $\pi \ldots \pi$ stacked molecules inside the surface and indicate that S. .H, C. .C, S. .O, C. .N , Ag. .O and $\mathrm{Ag}$...H interactions are appreciable in all the three complexes.

To highlight various intermolecular contacts like H...H, O...H, C...H, S...H, N...H, C...C, S...O, C...N, Ag...O and Ag...H, etc., decomposed fingerprint plots were generated (figures S1-S4). Such disintegration allows the separation of contribution from different kind of interactions. The outline of full fingerprint is shown in grey. The H...H interactions are reflected in the middle of scattered points in $2 \mathrm{D}$ plot and have the most significant contribution to Hirshfeld surfaces in complexes (I) and (II). These figures show that H. ..H interactions are noticeably more in complex (II) which can be accounted due to the large number of hydrogens in phSD $\left[\left(-\mathrm{CH}_{2}-\right)_{10}\right]$ ligand. Although both complexes (I) and (III) have $\mathrm{CH}_{2}-\mathrm{CH}_{2}-$ chain in the ligand but $\mathrm{H}$...H interactions are $40.2 \%$ and $11.7 \%$ respectively. This can be argued that due to the presence of $\mathrm{F}$ in the anion of (III), $\mathrm{H}$...F bonding predominates $(30 \%)$ which results in decreasing H. . .H contacts. The O...H interactions also show significant participation in crystal structure. For all the three complexes proportion of S. .H, and C. .C bonding is larger than other weak interaction kinds like C...C, S...O, C...N, Ag...O and Ag...H, etc. The inspection of contacts between other atom types point out that there are no other significant interactions. They collectively make $5.5,4.5$ and $13.7 \%$ of surface area.

\section{Conclusion}

The 2-D polymeric complex (I) has been crystallized in methanol-acetonitrile mixture, where each $\mathrm{Ag}(\mathrm{I})$ ion occupies distorted trigonal pyramidal geometry. $\operatorname{Ag}(\mathrm{I})$ is coordinating with two sulphur atoms from two different ligands and two oxygen atoms from two $\mathrm{NO}_{3}$ groups. Each $\mathrm{NO}_{3}$ acts as a bridging ligand coordinating through its two oxygen atoms to different $\mathrm{Ag}(\mathrm{I})$ ions. The $\mathrm{Ag}(\mathrm{I})$ ion and $\mathrm{NO}_{3}$ group are in plane with torsion angle $176.43^{\circ}$. All the ligands adopt anti-conformation but the relative orientation of two -S-C-C-S units is perpendicular to one another such that two phenyl rings attached to the two sulphur atoms coordinating to a particular Ag ion lie on the same side. Each $\mathrm{NO}_{3}$ bridges two neighbouring $\mathrm{Ag}$ ions belonging to two different $\mathrm{S}$-Ag-S-C-C-S-Ag-S- tapes running along $a$-axis where two phenyl rings are not parallel to each other to reduce the steric hindrance and maximize packing. There is a long cavity along $b$-axis where phenyl rings are placed and are within $\pi-\pi$ interaction range i.e., $3.851 \AA$. The structure consists of 4-c uninodal net where Point symbol for $\mathrm{Ag}(\mathrm{I})$ ion and net is $\left(4^{4} .6^{2}\right)$ with sql type topology. X-ray diffraction analysis and Hirshfeld surface analysis give rise to comparable results but in Hirshfeld surface analysis, two-third times more close contacts are obtained. The finger print plots demonstrate that these weak non-bonding interactions are important for stabilizing the crystal packing.

\section{Supplementary Information}

CCDC No. 1015744 contains supplementary crystallographic data for (I). This data can be obtained free of charge via http://www.ccdc.cam.ac.uk/conts/ retrieving.html, or from the Cambridge Crystallographic Data Centre, 12 Union Road, Cambridge CB2 1EZ, UK; fax: (+44) 1223-336-033; or e-mail: deposit@ccdc.cam.ac.uk. Figures S1-S4, table S1 can be seen in Supplementary I formation available at www. ias.ac.in/chemsci.

\section{Acknowledgements}

R K Mudsainiyan gratefully acknowledges UGC-BSR for financial assistance.

\section{References}

1. (a) Suenaga Y, Sowa T-K, Maekawa M and Munakata M 1996 J. Chem. Soc. Dalton Trans. 2737; (b) Awaleh M O, Brisse F, Soubaneh Y D, Maris T and Dirieh E S 2010 J. Inorg. Organomet. Polym. 20 816; (c) Awaleh M O, Badia A, Brisse F and Bu X-H 2006 Inorg. Chem. 451560 
2. Blake A J, Champness N R, Khlobystov A, Lemenovskii D A, Li W S and Schroder M 1997 J. Chem. Soc. Chem. Commun. 1339

3. Goodgame D M L, Grachovogel D A and Williams D J 2002 J. Chem. Soc. Dalton Trans. 2259

4. Dong Y B, Ma J P, Huang R Q, Smith M D and Loye H C Z 2003 Inorg. Chem. 42294

5. Horikoshi B, Mochida T, Maki N, Yamada $\mathrm{S}$ and Moriyama H 2002 J. Chem. Soc., Dalton Trans. 28

6. Schultheiss N, Powell D R and Bosch E 2003 Inorg. Chem. $\mathbf{4 2} 5304$

7. Carlucci L, Ciani G, Gudenberg D W V and Proserpio D M 1997 Inorg. Chem. 363812

8. Pan P, Woodlock E B, Wang X, Clam K and Rheingold A L 2001 J. Chem. Soc., Chem. Commun. 1762

9. Bu X-H, Chen W, Du M, Biradha K, Wang W-Z and Zhang R-H 2002 Inorg. Chem. 41437

10. Black J R, Champness N R, Levason W and Reid G 1995 J. Chem. Soc., Chem. Commun. 1277

11. Bu X-H, Chen W, Hou W F, Du M, Zhang R H and Brisse F 2002 Inorg. Chem. 413477

12. McKinnon J J, Spackman M A and Mitchell A S 2004 Acta Crystallogr. Sect. B 60627

13. SAINT, Version 6.36A; Bruker AXS: Madison WI 2001
14. Sheldrick G M, Siemens Area Correction Absorption Correction Program; University of Göttingen: Göttingen, Germany 1994

15. Altomare A, Cascarano G, Giacovazzo $\mathrm{C}$ and Guagliardi A 1993 J. Appl. Crystallogr. 26343

16. Sheldrick G M 2008 Acta Cryst. A A64 112

17. Sheldrick G M, SHELXL-97 Program for Crystal Structure Solution and Refinement; University of Göttingen: Göttingen, Germany 1997

18. Nardelli M 1983 Comput. Chem. (Oxford) 795

19. Farrugia L J 1997 J. Appl. Crystallogr. 30565

20. Allen F H 2002 Acta Cryst. B58 380

21. Farrugia L J 1999 J. Appl. Cryst. 32837

22. McKinnon J J, Jayatilaka D and Spackman M A 2007 Chem. Commun. 1

23. Li Y, Zhang C G, Cai L Y and Wang Z X 2013 J. Coord. Chem. 663100

24. Luo Y H, Mao Q X and Sun B W 2014 Inorg. Chim. Acta $\mathbf{4 1 2} 60$

25. Bakavoli M, Rahimizadeh M, Feizyzadeh B, Kaju A A and Takjoo R 2010 J. Chem. Crystallogr. 40746

26. Yazdanbakhsh M and Takjoo R 2008 Struct. Chem. 19895

27. Wawrzycka-Gorczyca I and Siwek A 2012 Struct. Chem. 231559 